\title{
AOR
}

Selected Papers of \#AolR2021:

The 22nd Annual Conference of the

Association of Internet Researchers

Virtual Event / 13-16 Oct 2021

\section{THE LIMITS OF FACT-CHECKING: EIGHT NOTES ON CONSENSUS REALITY}

Otávio Vinhas

University College Dublin

Marco Bastos

University College Dublin; City, University of London

\section{Introduction}

Considerable efforts and resources have been allocated to the fact-checking industry as a potential solution to correcting prior knowledge and offsetting the upsurge in hyperpartisanship that nurtures misinformation (Marietta \& Barker, 2019). The expansion of this industry is associated with a political context marked by the spread of misinformation (Lewandowsky, Ecker, Seifert, Schwarz, \& Cook, 2012), where trust in government and institutions, including news organizations, have markedly decreased (Amazeen, 2020; Zuckerman, 2017). Several organizations emerged that envisioned an expansion of journalistic practices devoted not only to selecting information but actively classifying information that is deemed to be true and therefore trustworthy and information that is false and, consequently, harmful to the public debate (Graves, 2016). The number of fact-checking organizations more than doubled since 2016, reaching 304 organizations in 84 different countries worldwide (Stencel \& Luther, 2020). As the industry expands as a partial solution to mitigate informational uncertainty and institutional distrust, its capabilities and limitations to counter the misinformation landscape should be reviewed.

The main tenet of fact-checking consists of verifying and correcting false claims to protect the democratic principles underpinning political deliberation. The practice is posited as the diametrical opposite of misinformation, providing evidence to rebut the inaccuracies advanced to mislead individuals (Jiang \& Wilson, 2018). However, while the fact-checking movement arises and establishes partnerships with social media platforms (Facebook, 2018a, 2018b; Twitter, 2019), practitioners are also shifting their focus to combat online misinformation (Graves \& Mantzarlis, 2020). This expansion is also designed to counter the growing distrust in democratic institutions, particularly the government and mainstream media (Amazeen, 2020; Zuckerman, 2017), while also 
offsetting the growing epistemic crisis manifested in reports about information disorders (Wardle \& Derakhshan, 2017). Yet, the rampant distribution of false content and the epistemic effects of its spreadability across social networks poses fundamental questions about fact-checking limitations in addressing problems that do not occur in isolation. Instead, these problems stem from broader social tensions, technological affordances, and partisan arrangements (Benkler, Faris, \& Roberts, 2018; Bennett \& Pfetsch, 2018; Lewandowsky, Ecker, \& Cook, 2017).

In this study we review the literature on fact-checking and the empirical evidence contending that it can correct prior knowledge and false information. We outline eight fundamental problems with fact-checking revolving around epistemology, methodology, implementation, polarization, bias, efficacy, ambiguity, ephemerality, objectivity, and criticism. We discuss these problems in relation to recent developments, including the establishment of fact-checking agencies across the world and national elections, both in Western countries and in the Global South that led to greater uncertainty despite intense fact-checking. In the following, we discuss in detail the unsurmountable limitations of fact-checking summarized in eight fundamental limitations.

\section{Discussion}

The four case studies discussed in this study foreground the shortcomings of factchecking in contexts where contentious politics took precedence over consensual reasoning. They also caution against normative parameters of valid speech, particularly in contexts of an institutional crisis of trust where hegemonic narratives are fraught and disputed by actors disengaged from consensus reasoning. The case studies also show that dissensus reality and conspiracy theorizing are not prerogatives of the far-right (Benkler et al., 2018), notwithstanding conservatives being reportedly more hostile towards fact-checkers in various countries (Lyons, Mérola, Reifler, \& Stoeckel, 2020; Shin \& Thorson, 2017).

The allegiances that underpin the misinformation landscape may be detached from ideological fault lines, feeding instead on epistemological cleavages where the establishment of facts is contingent on political and value-based perspectives. Fact checks thus reestablish the social order by resorting to forms of universal demarcation-including true/false, fact/fiction, and nature/spirit-principles that continue to orient journalistic practices (Waisbord, 2018). However, with social media communication allowing social groups to insulate themselves from conflicting information, it may not be possible for individuals to evaluate news or rely on factchecks based on the trust and authority of the original producer if they sit in opposition to their own modes of justification (Ekström \& Westlund, 2019).

\section{Conclusion}

We reviewed the literature in the area and argued that the central problem with factchecking is the premise that false information can be offset with more information and that facts are events universally agreed upon. We posit that the growing fact-checking industry is detached from the misinformation landscape and outline eight fundamental problems with fact-checking revolving around epistemology, implementation, bias, 
efficacy, ambiguity, objectivity, ephemerality, and criticism. We discuss these shortcomings in relation to the establishment of fact-checking agencies across the world and their role in national elections in the United Kingdom, United States, Malaysia, and Brazil. The article concludes with a discussion on the extent to which fact-checking may be effective against false information in a context where consensus reality has been super-imposed by individual reality.

\section{References}

Amazeen, M. A. (2020). Journalistic interventions: The structural factors affecting the global emergence of fact-checking. Journalism, 21(1), 95-111.

Benkler, Y., Faris, R., \& Roberts, H. (2018). Network Propaganda: Manipulation, Disinformation, and Radicalization in American Politics: Oxford University Press.

Bennett, W. L., \& Pfetsch, B. (2018). Rethinking Political Communication in a Time of Disrupted Public Spheres. Journal of Communication, 68(2), 243-253. doi:10.1093/joc/jqx017

Ekström, M., \& Westlund, O. (2019). The Dislocation of News Journalism: A Conceptual Framework for the Study of Epistemologies of Digital Journalism. Media and Communication, 7(1), 259-270. doi:10.17645/mac.v7i1.1763

Community Standards, (2018a).

Understanding the Facebook: Community Standards Enforcement Report, (2018b).

Graves, L. (2016). Deciding what's true: The rise of political fact-checking in American journalism. New York: Columbia University Press.

Graves, L., \& Mantzarlis, A. (2020). Amid Political Spin and Online Misinformation, Fact Checking Adapts. The Political Quarterly, 91, 585-591. doi:https://doi.org/10.1111/1467-923X.12896

Jiang, S., \& Wilson, C. (2018). Linguistic Signals under Misinformation and FactChecking. Proceedings of the ACM on Human-Computer Interaction, 2(CSCW), 1-23. doi:10.1145/3274351

Lewandowsky, S., Ecker, U. K., \& Cook, J. (2017). Beyond misinformation: Understanding and coping with the "post-truth" era. Journal of Applied Research in Memory and Cognition, 6(4), 353-369.

Lewandowsky, S., Ecker, U. K., Seifert, C. M., Schwarz, N., \& Cook, J. (2012). Misinformation and its correction: Continued influence and successful debiasing. Psychological science in the public interest, 13(3), 106-131. 
Lyons, B., Mérola, V., Reifler, J., \& Stoeckel, F. (2020). How Politics Shape Views Toward Fact-Checking: Evidence from Six European Countries. The International Journal of Press/Politics, 25(3), 469-492. doi:10.1177/1940161220921732

Marietta, M., \& Barker, D. C. (2019). One Nation, Two Realities: Dueling Facts in American Democracy. Oxford: Oxford University Press.

Shin, J., \& Thorson, K. (2017). Partisan Selective Sharing: The Biased Diffusion of FactChecking Messages on Social Media. Journal of Communication. doi:10.1111/jcom.12284

Stencel, M., \& Luther, J. (2020). Fact-checking count tops 300 for the first time [The Reporters' Lab finds fact-checkers at work in 84 countries -- but growth in the U.S. has slowed].

Political Content, (2019).

Waisbord, S. (2018). Truth is What Happens to News. Journalism Studies, 19(13), 1866-1878. doi:10.1080/1461670x.2018.1492881

Wardle, C., \& Derakhshan, H. (2017). Information Disorder: Toward an interdisciplinary framework for research and policy making. Retrieved from https://shorensteincenter.org/wp-content/uploads/2017/10/Information-DisorderToward-an-interdisciplinary-framework.pdf?x78124

Zuckerman, E. (2017). Mistrust, efficacy and the new civics: Understanding the deep roots of the crisis of faith in journalism. 